\title{
Terapia comportamental do transtorno obsessivo-compulsivo
}

\author{
Regina Christina W ielenska
}

Instituto de Psicologia da Universidade de São Paulo. São Paulo, SP, Brasil

\begin{abstract}
Behavior therapy, an experimentally-based approach, has been able to successfully treat obsessive-compulsive disorder by means of graded exposure to feared stimuli and response prevention procedures. This article will present the main treatment features, emphasizing behavioral assessment, motivational interviewing techniques, session planning guidelines, and issues on rehabilitation.
\end{abstract}

Keywords Obsessive-compulsive disorder. Behavior therapy. Therapeutic relationship.

\section{Introdução}

A terapêutica comportamental do transtorno obsessivocompulsivo (TOC) oferece, ao portador e a seus familiares, uma proposta eficaz, experimentalmente embasada, de atendimento individual ou em grupo. Entretanto, a replicação dos resultados referidos pela literatura depende de condições que serão discutidas ao longo do presente artigo. ${ }^{1-14}$

\section{Relação terapêutica e avaliação comportamental: bases do tratamento}

Geralmente, nas primeiras sessões, procede-se:

- à avaliação do paciente em relação ao TOC e a seu funcionamento global, identificando-se: queixa inicial; explicação e crítica a respeito de seu problema; contextos que favorecem o surgimento ou a atenuação dos sintomas; formas utilizadas para superação do TOC ou outras adversidades ao longo da história de vida; estressores psicossociais atuais ou passados; expectativas do cliente acerca do tratamento; sua história de busca de atendimento por essa queixa ou similares; seu repertório geral (social, acadêmico, profissional, verbal ou em qualquer outro nível); fontes disponíveis de gratificação (em termos mais rigorosos, os prováveis reforçadores naturais disponíveis ao paciente); etc.;

- ao treino do paciente para estabelecer relações entre suas queixas, características do TOC e possíveis prejuízos, objetivos e subjetivos, decorrentes do livre curso do quadro obsessivo-compulsivo. Esse aspecto é especialmente importante para facilitar a adesão ao tratamento;

- à caracterização cuidadosa do TOC e de suas eventuais comorbidades, por meio de entrevistas, observação (em consultório ou fora dele) e eventual aplicação de escalas. ${ }^{15,16}$ É fundamental identificar os tipos de obsessões e compulsões, sua frequiência e duração; estimar a intensidade do sofrimento gerado (ao se evitar, ou não, o ritual); rastrear prováveis antecedentes dos comportamentos de interesse clínico (eventos públicos, como situações sociais, ou privados, como um estado corporal, são igualmente capazes de favorecer a ocorrência dos sintomas); analisar as conseqüências de curto, médio e longo prazos (para o portador e para aqueles com quem convive) do comportamento obsessivocompulsivo;

- ao estabelecimento de um relacionamento terapêutico sólido. Descobrir-se portador de um transtorno psiquiátrico implica um maior risco de esquiva do tratamento, com ou sem o aval familiar. Rejeitar o diagnóstico ou buscar tratamentos "naturais", "alternativos" e lamentavelmente ineficazes (que, entretanto, parecem menos aversivos ou radicais) é reação compatível com a desinformação e o preconceito ainda vigentes no país. O bom relacionamento terapêutico serviria, ao paciente, de contraponto ao controle aversivo, propiciando seu engajamento na terapia. Recomenda-se instilar esperança (com dados baseados em evidências), sem promessas de remissão instantânea e completa dos sintomas. Recebem especial atenção os pacientes com tentativas de tratamento malsucedidas, seja por baixa adesão, má resposta aos fármacos, ocorrência de efeitos colaterais intensos e duradouros ou também pela presença de comorbidades psiquiátricas não-tratadas. Coagidos por familiares ou premidos pelo sofrimento, buscam auxílio "somente mais uma vez", podendo desistir a qualquer momento e perpetuando os prejuízos. Por fim, pacientes com pouca crítica de sua condição mórbida, ou que dela obtêm expressivo benefício interpessoal ou financeiro, também exigem cuidados diferenciados. ${ }^{17}$

Em suma, a fase inicial do tratamento comportamental do TOC tem por objetivo:

- construir um vínculo afetivo, coerente, respeitoso, entre paciente e terapeuta;

- identificar as prováveis variáveis ambientais das quais o comportamento obsessivo-compulsivo é função ou, em outros termos, realizar a análise funcional do comportamento; 
- ensinar ao paciente e familiares sobre as características do TOC e sobre seu tratamento, apontando soluções, incentivando sua participação no tratamento e prevenindo desistências. ${ }^{18}$

\section{Procedimentos básicos: exposição a estímulos ansiogênicos e prevenção de respostas ritualísticas}

A análise funcional do comportamento relaciona o contexto que antecede as obsessões às suas respectivas conseqüências. Por exemplo, os pensamentos de um paciente (sobre a segurança dos filhos) e seu comportamento de assegurar que tudo estivesse bem aumentavam significativamente de frequiência nas semanas que antecediam a negociação de seu aluguel residencial (que subia em descompasso com suas posses e rendimentos). Para outra pessoa, o contato físico ou visual com palmeiras ou árvores similares produzia obsessões (sobre morte ou enfermidades), forçando o cliente a repetir qualquer ação que estivesse desempenhando durante seu contato com a árvore, mas, dessa vez, "tendo a certeza de pensar em algo bom para neutralizar o perigo". Para ambos os clientes, um relativo alívio sucedia aos rituais, que se mantinham em altas taxas, caracterizando uma contingência de reforçamento negativo de respostas de fuga e esquiva. Os intervalos progressivamente menores de bem-estar e um crescente desconforto os conduziam de volta a rituais ou esquivas mais elaborados (vigiar mais vezes as crianças, esquivar-se de locais onde já soubesse existir palmeiras). Demonstrando-se a ruptura entre o custo do ritual e o benefício supostamente obtido, é o momento de propor ao paciente caminhos para tratamento do TOC e dos demais aspectos que se mostrarem necessários.

O tratamento é norteado pela idéia de que ele precisará correr os riscos potenciais que evita ao emitir esquivas e rituais. $\mathrm{O}$ subproduto direto desta exposição é uma nítida ativação emocional (gerada pela forma não-obsessiva de contato com o mundo). O paciente não será impedido de "pensar o que pensa e de sentir o que sente", mas precisa ser levado a "viver o que evita sentir" enquanto se expõe (geralmente ele supõe que sentirá níveis insuportáveis de medo, desconforto físico, sensação de incompletude, imperfeição, perigo ou ameaça). Ao terapeuta cabe criar meios para o portador de TOC "pensar propositadamente no que evita pensar, fazer deliberadamente o que tende a evitar e, por fim, renunciar aos recursos que usa para se sentir bem". Com os progressos da exposição, poderá descobrir que o forte sofrimento desaparece lentamente, mesmo sem a emissão de rituais.

- Pacientes perguntam como saber se estarão seguros ou não. Sugere-se responder que: "não há certeza absoluta. As pessoas parecem correr os riscos que você evita. A despeito de um perigo potencial, a vida dos outros parece fluir melhor; eles vivem prazeres e também, se problemas ocorrem, sobra-lhes força para resolvê-los" ou "você precisará escolher entre a escravidão do TOC ou os riscos assumidos implicitamente por quem se sente livre. Em alguns casos, todos diriam que, se um risco é real, mas tem baixa probabilidade de ocorrência e produz danos de pequena monta, não há razão para rituais e esquivas.
Se os riscos forem pouco prováveis, mas com danos significativos, o tratamento caminhará até o ponto em que as outras pessoas procuram se acautelar, nem mais nem menos. Usaremos o que for consenso para a cultura. Por exemplo, não se obriga alguém com obsessão de contaminação por Aids a ter contato sexual sem preservativo apenas para desenvolver tolerância, habituação emocional ao perigo. Mas as pessoas não lavam seus calçados ao pisar em manchas cuja cor parece com sangue e tampouco evitam falar palavras como Aids e positivo por temer contaminação. Pode até ser que todos tenham certeza da impossibilidade de ocorrer aquilo que você teme, mas reconheço que houve uma época em que todos consideraram Oswaldo Cruz um maluco. Se Galileu Galilei foi visto como um herege, e o átomo já pareceu ficção científica, tudo é possível. Mas você precisará renunciar aos teus métodos se quiser viver de verdade. Quero brigar com o TOC, não com você, e arrisco meu diploma propondo o enfrentamento, passo a passo, dos riscos inerentes à condição de todo ser humano”.

É fundamental que o terapeuta regule a profundidade e o tipo de linguagem que adotar conforme os atributos do paciente (idade, nível sociocultural, tipos de sintomas, capacidade de prestar atenção a explicações e de compreender questões como as expostas acima). Livros, filmes, websites cientificamente atualizados e conversas com quem se beneficiou do tratamento são bons coadjuvantes. ${ }^{18}$

No primeiro caso relatado, a terapia enfocou o treino de habilidades para lidar com fontes de estresse (técnicas de negociação, planejamento financeiro e adoção de um estilo de vida realisticamente compatível com as posses do paciente, avaliação de novas alternativas de rendimentos etc.) bem como o manejo do TOC por técnicas de exposição gradual aos pensamentos de perigo, sempre associadas à prevenção de respostas (evitar os rituais de checagem). Observou-se a redução gradual das obsessões, das compulsões e da exacerbação emocional.

No segundo exemplo, o paciente foi exposto tanto aos pensamentos temidos, por meio da repetição prolongada dos conteúdos obsessivos (em voz alta, depois apenas para si próprio e por fim escrevendo cada obsessão) como a diferentes palmeiras, estando impedido de emitir comportamentos de neutralização. Como sempre, a meta foi provocar a habituação emocional aos estímulos ansiogênicos, sendo os progressos avaliados segundo parâmetros objetivos e subjetivos.

\section{Cuidados na implementação dos procedimentos e finalização do tratamento}

O encerramento de cada sessão de exposição define-se pela significativa redução da ativação emocional, estando a pessoa frente ao estímulo aversivo, não emitindo rituais. Convém delinear uma hierarquia desses estímulos, graduando-se intensidades. $\mathrm{O}$ tratamento se inicia com o enfrentamento de algo razoavelmente tolerável, e, vencida essa etapa, tem início outro exercício, com estímulos situados em pontos mais avançados da hierarquia. Embora deva-se combater esquivas 
encobertas ("mentais"), o uso, na sessão, do humor, de relaxamento muscular e respiratório, de pausas breves e de técnicas de distração temporária pode ajudar o paciente a suportar o enfrentamento. Álcool e benzodiazepínicos são banidos do processo, resguardando-se integralmente a reatividade emocional ao meio ambiente durante a exposição. Acompanhantes terapêuticos ${ }^{19}$ e familiares, sob estrita supervisão e treinamento, colaboram na execução dos exercícios apenas quando sua par- ticipação não gerar conflitos interpessoais adicionais. Aliás, a terapia familiar é indicada se as relações familiares estiverem comprometidas devido ao TOC. Vencidos os sintomas, a intervenção comportamental volta-se à construção das habilidades que se degradaram ao longo da enfermidade ou sequer puderam surgir (geralmente de cunho social, acadêmico e profissional), facilitando ao portador do TOC conquistar a qualidade de vida há muito esquecida.

\section{Referências}

1. Maier NRF. Frustration: the study of behavior without a goal. New York: McGraw-Hill; 1947.

2. Wolpe J. Psychotherapy by reciprocal inhibition. Stanford: Stanford University Press; 1958.

3. Meyer V. Modification of expectations in cases with obsessional rituals. Behav Res Ther 1966;4:273-80.

4. Baum M. Rapid extinction of an avoidance response following a period of response prevention in the avoidance apparatus. Psychol Report 1966;18:55-64.

5. Rachman S, Hodgson R, Marks IM. The treatment of chronic obsessive-compulsive neurosis. Behav Res Ther 1971;9:237-47.

6. Wolpe J. The practice of behavior therapy. New York: Pergamon Press; 1969.

7. Boulougouris J, Masrset P, Marks IM. Superiority of flooding (implosion) to desensitization for reducing pathological fear. Behav Res Ther 1971;8:7-16.

8. Stampfl TG, Levis DJ. Essentials of implosive therapy: a learningtheory-based psychodynamic behavioral therapy. J Abn Psychol 1967;72:496-503.

9. Marks IM. Fears, Phobias and Rituals. London: Oxford University Press; 1987.

10. Foa EB, Wilson R. Venza sus obsesiones. Barcelona: Ediciones RobinBook; 1992.

11. Wielenska RC, Araújo LAB, Bernik, MA. Transtorno obsessivocompulsivo. In: Rangé B, org. Psicoterapia comportamental e cognitiva de transtornos psiquiátricos. Campinas: Editorial Psy; 1995. p. $105-14$.
12. Ross J. Vencendo o medo. São Paulo: Objetiva; 1997.

13. Yaryura-Tobias JA, Neziroglu F. Biobehavioral Treatment of Obsessive-Compulsive Spectrum Disorders. New York: W. W. Norton; 1997.

14. Goodman WK, Rasmussen SA, Price LH, Riddle MA, Rapoport JL Children's Yale-Brown Obsessive-Compulsive Scale (CYBOCS). 1st ed. Departments of Psychiatry of Yale and Brown Universities and Child Psychiatry Branch, National Institute of Mental Health; 1986.

15. Goodman WK, Price LH, Rasmussen AS, Mazure C, Heninger GR, Charney DS. The Yale-Brown Obsessive Compulsive Scale: development, use and reliability. Arch Gen Psychiatry 1989;46:1006-11.

16. Chiles JA, Carlin AS, Benjamin GAH, Beitman BD. A physician, a nonmedical psychotherapist, and a patient: the pharmacotherapy-psychotherapy triangle. In: Beitman BD, Klerman GL, orgs. Integrating pharmacotherapy and psychotherapy. Washington (DC): American Psychiatric Press; 1991. p. 105-18.

17. Wielenska RC. Transtorno obsessivo-compulsivo na infância e adolescência. In: Silvares EFM, org. Estudos de caso em psicologia clínica comportamental infantil. v. 2. Campinas: Papirus; 2000.

18. Zamignani DR, Wielenska RC. Redefinindo o papel do acompanhante terapêutico. In: Kerbauy RR, Wielenska RC, orgs. Sobre comportamento e cognição: da reflexão teórica à diversidade na aplicação. v. 4. Santo André: Arbytes; 1999.

Correspondência: Regina Christina Wielenska

Rua Itapeva, 490, conj. 56, Bela Vista - 01332-902 São Paulo, SP, Brasil

E-mail :wielensk@uol.com.br 